\title{
BMJ Open High risk of adverse events in hospitalised hip fracture patients of 65 years and older: results of a retrospective record review study
}

\author{
Hanneke Merten, ${ }^{1,2}$ Paul C Johannesma, ${ }^{3}$ Sanne Lubberding, ${ }^{1}$ Marieke Zegers, ${ }^{1}$ \\ Maaike Langelaan, ${ }^{1}$ Gerrolt N Jukema, ${ }^{4}$ Martin J Heetveld ${ }^{5}$ Cordula Wagner ${ }^{1,2}$
}

To cite: Merten $\mathrm{H}$ Johannesma PC,

Lubberding $\mathrm{S}$, et al. High risk of adverse events in hospitalised hip fracture patients of 65 years and older: results of a retrospective record review study. BMJ Open 2015:5: e006663. doi:10.1136/ bmjopen-2014-006663

- Prepublication history and additional material is available. To view please visit the journal (http://dx.doi.org/ 10.1136/bmjopen-2014006663).

Received 17 September 2014 Revised 9 March 2015 Accepted 12 March 2015



For numbered affiliations see end of article.

Correspondence to Hanneke Merten; h.merten@vumc.nl

\section{ABSTRACT \\ Objectives: Hip fracture patients of 65 years and older are a complex patient group who often suffer from complications and difficult rehabilitation with disappointing results. It is unknown to what extent suboptimal hospital care contributes to these poor outcomes. This study reports on the scale, preventability, causes and prevention strategies of adverse events in patients, aged 65 years and older, admitted to the hospital with a primary diagnosis of hip fracture.}

\section{Design, setting and outcome measures:}

A retrospective record review study was conducted of 616 hip fracture patients ( $\geq 65$ years) admitted to surgical or orthopaedic departments in four Dutch hospitals in 2007. Experienced physician reviewers determined the presence and preventability of adverse events, causes and prevention strategies using a structured review form. The main outcome measures were frequency of adverse events and preventable adverse events in hospitalised hip fracture patients of 65 years and older, and strategies to prevent them in the future.

Results: 114 (19\%) of the 616 patients in the study experienced one or more adverse events; 49 of these were preventable. The majority of the adverse events $(70 \%)$ was related to the surgical procedure and many resulted in an intervention or additional treatment $(67 \%)$. Human causes contributed to $53 \%$ of the adverse events, followed by patient-related factors $(39 \%)$. Training and close monitoring of quality of care and the health professional's performance were the most often selected strategies to prevent these adverse events in the future.

Conclusions: The high percentage of preventable adverse events found in this study shows that care for older hospitalised hip fracture patients should be improved. More training and quality assurance is required to provide safer care and to reduce the number of preventable adverse events in this vulnerable patient group.

\section{INTRODUCTION}

Owing to the ageing population in Western countries, the number of patients with a hip

\section{Strengths and limitations of this study}

- This study included more than 600 records of patients, aged 65 and older, admitted to the hospital with a primary diagnosis of hip fracture to examine the scale, preventability, causes and prevention strategies of adverse events in this vulnerable patient group.

- The methods of this study were based on the well-established structured retrospective record review method. In addition, the reviewers had extensive experience in surgical treatment of hip fractures and in the retrospective record review method.

- Retrospective record review has limitations: the review process relies on the judgements of the reviewers and they can only use the information that is available in the record.

- The inter-rater agreement between reviewers for the determination of a complication was substantial, but moderate for the determination of an adverse event.

- Gathering a complete overview of the contributing causes of (preventable) adverse events is difficult when using retrospective record review. It is likely that not all information, especially on organisational and technical factors, is included in the record.

fracture is expected to increase considerably. ${ }^{12}$ Hip fractures occur predominantly in older persons. They often suffer from comorbidities, which is associated with an increased risk of rehospitalisation and mortality. ${ }^{3}$

Most hip fracture patients undergo surgery and face a long rehabilitation process with often disappointing results. To illustrate, research has shown that hip fractures have a negative effect on health-related quality of life and activities of daily living. ${ }^{4}$ In general, an increased likelihood of morbidity, disability and mortality are identified as main consequences of a hip fracture. ${ }^{5}{ }^{6}$ It remains 
unclear, however, to what extent errors in healthcare management may be a contributing factor to these negative outcomes and whether these can be prevented.

In several countries, retrospective medical record review studies have been conducted to gain insight into the incidence, preventability and causes of adverse events (AEs) in hospitals. ${ }^{7} \mathrm{An} \mathrm{AE}$ is defined as an unintended injury that results in temporary or permanent disability, death or prolonged hospital stay, and is caused by healthcare management rather than by the patient's underlying disease process. ${ }^{8}$ For Western countries in general, a mean overall incidence of inhospital AEs was estimated at $9.2 \%$. Moreover, nearly half of these AEs were classified as preventable. ${ }^{7}$ In the Netherlands, Zegers et al, ${ }^{9}$ showed that one or more AEs were found in 5.7\% of all Dutch hospital admissions and a preventable $\mathrm{AE}$ was found in $2.3 \%$ of all hospital admissions. These incidence rates describe the situation for the general hospital population. To our knowledge, no specific results on AE rates and their preventability are available for hip fracture patients; thus, it is still unknown to what extent suboptimal hospital care contributes to poor outcomes in this patient group. Therefore, the aim of our study was to report on the scale, preventability, causes and prevention strategies of AEs in patients, aged 65 and older, admitted to the hospital with a primary diagnosis of hip fracture.

\section{METHODS}

A structured retrospective medical record review study was conducted. Four hospitals participated in this study; 1 university, 2 tertiary teaching and 1 general hospital. The methods and instruments used in this study were based on the Harvard Medical Practice Study. ${ }^{8}$ The method has been modified in subsequent studies. ${ }^{10-15}$ In our study, instead of a 2-stage review process with nurses screening the records in the first stage, we only used experienced physician reviewers and let them screen all the records. We considered all our patients at high risk of suffering from an $\mathrm{AE}$, making the first screening stage redundant. From each hospital, all admissions in 2007 of patients, aged 65 and older, admitted to the hospital with a primary diagnosis of hip fracture were selected using the hospital administration data with a maximum of 200 patients per hospital. One hospital had more than 200 patients, so a random sample was selected. Pathological fractures, polytraumas and patients with fractures who did not undergo surgery were excluded from this selection due to differences in the required medical treatment.

Nine physician reviewers received a 2-day training in record review and a specific half-day training for this study in which the review form was explained and discussed; they were also provided with several cases for practice. The reviewers were retired surgeons (less than 7 years of retirement) with at least 15 years of clinical experience in surgery and actively involved with the treatment of hip fractures during their career. The review period was between June 2008 and July 2009. Nine per cent (55 records) of the records were independently reviewed by a second physician reviewer to determine an inter-rater reliability rate. For the review process, the reviewers used the medical, nursing and outpatient records and the images made during and after hospital stay. The time-frame of the review period was from the moment of admission until 6 months after discharge of the patient. These 6 months after discharge made it possible to also record AEs that are a result of the hospital admission, but were detected in the following outpatient visits. The reviewers used a standardised procedure and review form. They first had to register general patient characteristics and comorbidities. They made an inventory of all known comorbidities and categorised the level of comorbidity based on their expert judgement as: none, insignificant, moderate or significant comorbidity. Next, they had to determine the presence of complications and AEs, followed by the degree of preventability and prevention strategies.

In addition to AEs, the following concepts were used in the study. A complication is an unintended and unwanted outcome during or following medical treatment that requires the healthcare professional to adjust the treatment or when irreparable damage has occurred. ${ }^{16}$ It is broader than an AE because it can also be the result of a calculated risk. A preventable adverse event is an $\mathrm{AE}$ resulting from an error in management due to failure to follow accepted practice at an individual or system level. Accepted practice was defined as 'the current level of expected performance for the average practitioner or system that manages the condition in question'. ${ }^{17}$ Preventability was measured on a 6-point scale; an $\mathrm{AE}$ was considered preventable with a score of 4 and higher. For a more detailed description of the outcome measures, see box 1 .

When an $\mathrm{AE}$ was present, the reviewers had to determine one or more underlying causal factors and for preventable AEs, also the possible prevention strategies. The causal factors and prevention strategies were based on the PRISMA classification system and the Canadian Adverse Events Study. ${ }^{10} 1819$ The reviewers selected the causal factors and potential prevention strategies based on information in the patient record and their perception of the situation. They had the option to choose from five main causal categories: technical, organisational, human, patient-related and other causes. Technical causes involve problems with physical items such as equipment, software and materials. Organisational causes indicate problems with protocols and procedures, transfer of knowledge, management priorities and safety culture. Human causes can be described as the unsafe acts committed by the people who are in direct contact with the patient or the system. Actions they perform or decisions they make may result in errors that can have an immediate impact on safety. This, however, does not automatically mean that the $\mathrm{AE}$ 


\section{Box 1 Definitions and outcome measures ${ }^{17}$}

\section{Adverse Event determination}

$\mathrm{AE}$ determination was based on the presence of three criteria:

- an unintended (physical and/or mental) injury, which

- resulted in temporary or permanent disability, death or prolongation of hospital stay and was

- caused by healthcare management rather than the patient's disease

\section{Causation}

To determine whether the injury was caused by healthcare management or the disease process a six-point scale was used:

1. (Virtually) no evidence for management causation

2. Slight to modest evidence of management causation

3. Management causation not likely (less than $50 / 50$, but 'close call')

4. Management causation more likely (more than 50/50, but 'close call')

5. Moderate to strong evidence of management causation

6. (Virtually) certain evidence of management causation

Causation scores of 4-6 were classified as AEs.

Timing of AEs

The index hospital admission was the sampled admission for the hip fracture. AEs were included if they occurred during the index admission and were detected during or within 6 months after the index admission.

Preventability

The degree of preventability of AEs was measured on a six-point scale, grouped into three categories:

No preventability

1. (Virtually) no evidence for preventability

Low preventability

2. Slight to modest evidence of preventability

3. Preventability not quite likely (less than $50 / 50$, but 'close call') High preventability

4. Preventability more than likely (more than $50 / 50$, but 'close call')

5. Strong evidence of preventability

6. (Virtually) certain evidence of preventability

AEs with preventability scores of 4-6 were defined as preventable AEs

was preventable in retrospect. Patient-related causes are related to patient characteristics or conditions that are beyond the control of staff and which influence the treatment. Finally, other causes are failures that cannot be classified in another category. ${ }^{20-22}$ Next, for each preventable $\mathrm{AE}, 1$ or more of the following 10 prevention strategies could be selected by the reviewers: Technology/Equipment, Procedures, Information and Communication, Training, Motivation, Upscaling, Evaluation, Quality Assurance/Peer review, Financial Investment and Personnel. The prevention strategies are described in more detail in the results section.

All statistical analyses were performed using SPSS V.18.0. Patient characteristics, complications, AEs, preventable AEs, causes and prevention strategies were analysed using descriptive statistics and frequency tables. Difference in median length of hospital stay between hospitals was tested with a median test for independent samples. Differences in AEs between groups were tested with $\chi^{2}$ tests. For the inter-rater agreement between physicians, the percentage of agreement and a $\kappa$-statistic was calculated for the determination of complications and AEs. The classification system of Landis and Koch ${ }^{23}$ was used for the interpretation of the $\kappa$-statistic. The study and methods have been granted ethical approval by the medical ethical review board of the VU University Medical Center, Amsterdam, the Netherlands.

\section{RESULTS}

In total, the records of 616 patients, aged 65 and older, admitted to the hospital with a primary diagnosis of hip fracture were reviewed; table 1 describes the patient characteristics and complications during hospitalisation. Three-quarters of the patients were females and most patients were admitted to the surgical department. During admission, 35 (5.7\%) patients died. Of the other patients, almost half were discharged to a nursing home after the hospital admission. For $43 \%$ of all patients, 1 or more complications were registered in the patient record; delirium $(11 \%)$ was the most common complication. The reliability of the assessment on the occurrence of a complication was substantial $(\kappa=0.70)$, the percentage of agreement was $85 \%$. The mean age of the admitted hip fracture patients varied between the hospitals from 82.7 to 84.5 years. The overall median length of hospital stay was 11 days, with a range between 2 and 147 days. The median hospital stay differed significantly between hospitals $\left(\mathrm{X}_{3}^{2}=9.41, \mathrm{p}=0.024\right)$; posthoc analysis showed a significant difference between hospital 2 and 3 in the median length of stay (9 vs 12 days, $\mathrm{X}_{1}^{2}=9.41$, $\mathrm{p}=0.003)$. Patients with a short length of stay were mostly transferred to a psychogeriatric facility within a nursing home for more specialised care.

Table 2 describes the occurrence of AEs and preventable AEs in the study sample. In total, 124 AEs were found in 114 patient records. This means that in $19 \%$ of these hip fracture patients one or more AEs were detected. In total, 49 of these AEs $(40 \%)$ were judged to be preventable. There were no significant differences for gender or age category $(65-75,76-85,>85$ years) in the occurrence of AEs and preventable AEs. The agreement between reviewers for the determination of the presence of an $\mathrm{AE}$ was $85 \%$ with a $\kappa$-value of 0.52 , which can be classified as moderate. For the preventable AEs, no $\kappa$-statistic could be calculated since only 4 preventable AEs were included for a second review. For two AEs, both reviewers agreed that it was potentially preventable. For 1 $\mathrm{AE}$, the first reviewer judged the preventability as more than likely (score 4), while the second reviewer judged the preventability as not quite likely (score 3 ). The fourth $\mathrm{AE}$ was not judged as an AE by the second reviewer.

The analyses for the different fracture types showed a relatively high $\mathrm{AE}$ rate with femoral neck fractures $(21 \%)$ and subtrochanteric (24\%) hip fractures, compared to the other fracture types, but these differences 
Table 1 Patient characteristics and complications during hospitalisation

\begin{tabular}{|c|c|}
\hline Population characteristics & $\begin{array}{l}\text { Frequency } \\
\text { (valid \%) }\end{array}$ \\
\hline \multicolumn{2}{|l|}{ Distribution of records } \\
\hline Hospital 1 & $200(33)$ \\
\hline Hospital 2 & $132(21)$ \\
\hline Hospital 3 & $162(26)$ \\
\hline Hospital 4 & $122(20)$ \\
\hline Gender: female & $469(76)$ \\
\hline \multicolumn{2}{|l|}{ Admission department } \\
\hline Surgery & $489(81)$ \\
\hline Orthopaedics & $86(14)$ \\
\hline Trauma surgery & $27(4)$ \\
\hline Other & $5(1)$ \\
\hline \multicolumn{2}{|l|}{ Discharge status } \\
\hline Alive & $580(94)$ \\
\hline Deceased & $35(6)$ \\
\hline \multicolumn{2}{|l|}{ Discharge to } \\
\hline Nursing home & $271(48)$ \\
\hline $\begin{array}{l}\text { Transfer department within the } \\
\text { hospital }\end{array}$ & $73(13)$ \\
\hline Home with care & $66(12)$ \\
\hline Home for the elderly & $60(11)$ \\
\hline Home without care & $44(8)$ \\
\hline Rehabilitation centre & $25(4)$ \\
\hline Other & 27 (4) \\
\hline \multicolumn{2}{|c|}{ Number of complications during the index admission } \\
\hline 0 & $352(57)$ \\
\hline 1 & $148(24)$ \\
\hline 2 & 81 (13) \\
\hline$\geq 3$ & $35(6)$ \\
\hline \multicolumn{2}{|c|}{ Type of complication during the index admission } \\
\hline Delirium & $70(11)$ \\
\hline Ischaemia/heart failure & $37(6)$ \\
\hline Urinary tract infection & $30(5)$ \\
\hline Pneumonia & $30(5)$ \\
\hline Wound infection & $28(5)$ \\
\hline Bleeding/haematoma & $20(3)$ \\
\hline Other, unspecified complications & $52(8)$ \\
\hline Age of patients & $\begin{array}{l}\text { Mean age (SD) } \\
\text { (in years) }\end{array}$ \\
\hline Hospital 1 & $84.0(7.9)$ \\
\hline Hospital 2 & $83.0(7.0)$ \\
\hline Hospital 3 & $84.5(7.4)$ \\
\hline Hospital 4 & $82.7(7.6)$ \\
\hline Length of hospital stay ${ }^{*}$ & $\begin{array}{l}\text { Median number } \\
\text { of days (range) }\end{array}$ \\
\hline Hospital 1 & $11(2-67)$ \\
\hline Hospital 2 & $9(2-84) \ddagger$ \\
\hline Hospital 3 & $12(3-147) \ddagger$ \\
\hline Hospital 4 & $11(2-107)$ \\
\hline
\end{tabular}

were not significant. Preventable AEs occurred relatively often in subtrochanteric hip fractures (17\%), but this difference was also not significant. When distributed over the different operation procedures, no significant differences were detected for the occurrence of AEs and preventable AEs, although preventable AEs occurred most frequently when a long gammanail was placed $(15 \%)$. AEs occurred significantly more often in patients with a significant level of comorbidity $(25 \%)$ compared to the other groups $\left(\mathrm{X}_{3}^{2}=11.97, \mathrm{p}=0.007\right)$. AEs were preventable in $9 \%$ of the patients with significant comorbidity; this was not significantly different from the other comorbidity categories.

After establishing that an $\mathrm{AE}$ was present, these were classified by clinical procedure and the consequences were determined. Table 3 reports these outcomes for all 124 identified AEs and 49 preventable AEs. The majority of the AEs $(70 \%)$ and preventable AEs $(71 \%)$ were related to the surgical procedure itself. AEs and preventable AEs resulted most often in additional treatment or intervention, prolonged hospital stay or readmission to the hospital. For 6 of the 35 deceased patients, a preventable $\mathrm{AE}$ contributed substantially to their death; these are the potentially preventable deaths.

Next, the reviewers assessed what were the underlying causal factors for the occurrence of the AE. For 14 of the 124 AEs, the reviewers did not select a causal factor. Consequently, these AEs were removed from the causal factor analyses. In total, 180 causes were selected for the remaining 110 AEs. The total number of selected causal factors in the 49 preventable AEs is 84 . Figure 1 shows how often the five causal factors were selected and the percentage of AEs for which this factor was a cause. No K-statistic could be calculated for the inter-reliability of this judgement since there were not enough AEs in relation to the number of causal categories. For two AEs there was complete agreement between the reviewers in the selected causal categories. For 2 AEs, the second reviewer did not fill out any causes, for 2 other AEs, the first reviewer identified patient-related causes and the second reviewer selected the causal category 'not to be determined/other'.

Figure 1 shows that human causes predominantly contributed to the occurrence of AEs (53\% of AEs); for example, when an antibiotics allergy of a patient was missed by the nurse on the ward although this had been documented in the emergency room. The second main cause was the patient-related factor, such as severe preexisting diseases like heart failure; this contributed to $39 \%$ of the AEs. Human and organisational factors had a relatively high proportion of AEs that were preventable. Out of all AEs that had at least one human cause, $62 \%$ was considered preventable; for organisational factors this was $83 \%$.

Finally, the physician reviewers had to indicate which prevention strategies they considered useful to prevent the $\mathrm{AE}$ in the future. For the 49 preventable AEs, they selected 110 prevention strategies. These are described in table 4.

Improvement of training programmes for required skills $(51 \%)$ and continuous peer review/monitoring of quality $(51 \%)$ were both selected for the prevention of half of the preventable AEs. An example of a 
Table 2 Frequencies of AEs and preventable AEs by gender, age category, fracture type, operation procedure and level of comorbidity

\begin{tabular}{lccc}
\hline & $\begin{array}{c}\text { Records reviewed: } \\
\text { frequency (n (\%)) }\end{array}$ & $\begin{array}{l}\text { Of which contained } \\
\text { one or more AEs: } \\
\text { frequency (valid row \%) }\end{array}$ & $\begin{array}{l}\text { Of which contained one } \\
\text { or more preventable AEs: } \\
\text { frequency (valid row \%) }\end{array}$ \\
\hline $\begin{array}{l}\text { Total study sample } \\
\text { Gender }\end{array}$ & $616(100)$ & $114(19)$ & $49(8)$ \\
$\quad$ Male & $147(24)$ & $31(21)$ & $16(11)$ \\
Female & $469(76)$ & $83(18)$ & $33(7)$ \\
Age category (years) & & & \\
$65-75$ & $95(15)$ & $20(21)$ & $9(9)$ \\
$76-85$ & $254(41)$ & $51(20)$ & $21(8)$ \\
$>85$ & $267(43)$ & $43(16)$ & $19(7)$ \\
Fracture type & $309(50)$ & $65(21)$ & $24(8)$ \\
Femoral neck & $242(39)$ & $35(14)$ & $16(7)$ \\
Pertrochanteric & $46(7)$ & $11(24)$ & $8(17)$ \\
Subtrochanteric & $17(3)$ & $2(12)$ & $0(0)$ \\
Lateral & & $52(22)$ & $20(8)$ \\
Operation procedure & $239(39)$ & $27(14)$ & $14(7)$ \\
Femoral head replacement & $194(31)$ & $21(19)$ & $9(8)$ \\
Gammanail & $112(18)$ & $10(26)$ & $6(15)$ \\
Sliding hip screw & $39(6)$ & $3(12)$ & $0(0)$ \\
Long gammanail & $25(4)$ & $1(17)$ & $0(0)$ \\
Cannulated hip screws & $6(1)$ & $4(11)$ & $1(3)$ \\
Total hip replacement & & $12(12)$ & $7(7)$ \\
Judged level of comorbidity & $35(6)$ & $35(15)$ & $18(8)$ \\
None & $101(16)$ & $54(25)^{\star}$ & $19(9)$ \\
Insignificant & $228(37)$ & & \\
Moderate & $215(35)$ & from &
\end{tabular}

preventable $\mathrm{AE}$ in which more training was recommended is when the performed surgery was too drastic (femoral head replacement) even though cannulated screws were also sufficient. Online supplementary appendix 1 describes more examples of adverse events, their causal factors and prevention strategies.

\section{DISCUSSION}

The results show that almost one-fifth of the hip fracture patients in our study experienced an AE related to their hospital admission and almost $40 \%$ of these AEs were potentially preventable. Not surprisingly, AEs occurred more often in patients with significant comorbidity. These patients have severe other medical problems which complicates care. Therefore, it is often not possible to prevent these AEs and this was confirmed by the results: there were no significant differences in the rate of preventable AEs between the comorbidity levels. This, however, does not suggest that this finding is of no clinical relevance since this could also be the result of a lack of power to detect significant differences for the preventable AEs. The high percentage of AEs in patients with significant comorbidity may be a good starting point for future development in the care for this patient group; AEs that are currently not preventable, may become preventable in the future by advances in technology, education and care. The causes of AEs were, in more than half of the cases, related to human error. AEs with human and organisational causal factors were often preventable. The improvement of training for the skills needed for the treatment of this patient group in general and emphasis on quality assurance are two strategies that could be useful to prevent AEs in the future.

Our results show that the percentage of AEs and preventable AEs is two-and-a-half times higher for older hip fracture patients than the incidence rates in the general Dutch hospital population of 65 years and older. ${ }^{24}$ One explanation for this difference could be that older hip fracture patients are a difficult patient group to manage clinically, which makes this group more at risk of suffering from AEs. This could be supported by other studies showing high numbers of adverse outcomes in hip fracture patients. For example, Sathiyakumar et $a l^{25}$ found an $\mathrm{AE}$ rate of $25.2 \%$ in their database study in which they classified complications in hip fracture patients as major or minor AEs. Another factor for the high percentages found in our study may be that we used only physician reviewers in our review process; perhaps more AEs were found because the physician reviewers were required to look at all patient records instead of only receiving the triggered records from nurse reviewers. 
Table 3 Frequencies of AEs and preventable AEs categorised by clinical procedure and consequences

\begin{tabular}{lcc} 
& $\begin{array}{c}\text { AEs: N (\%) } \\
\text { (N=124) }\end{array}$ & $\begin{array}{c}\text { Preventable } \\
\text { AEs: N (\%) (N=49) }\end{array}$ \\
\hline Classification by clinical procedure* & $87(70)$ & $35(71)$ \\
Surgical procedure (operative procedures) & $4(8)$ \\
Medical procedures (procedure not in operating room) & $13(10)$ & $4(8)$ \\
Diagnostic process (eg, missed, delayed or inappropriate diagnostic process) & $9(7)$ & $4(8)$ \\
Medication (eg, side effects, allergic reactions, anaphylaxis) & $7(6)$ & $1(2)$ \\
Other clinical management (including nursing and allied healthcare) & $5(4)$ & - \\
Other (eg, fall) & $1(1)$ & - \\
Discharge procedure (eg, inappropriate discharge) & - & $1(2)$ \\
Missing & $2(2)$ & $35(71)$ \\
Consequencesł & & $20(41)$ \\
Intervention/treatment & $83(67)$ & $16(33)$ \\
Prolonged hospital stay & $43(35)$ & $15(31)$ \\
Readmission to hospital & $36(29)$ & $6(12)$ \\
Health limitation at discharge & $28(23)$ & $8(16)$ \\
Death & $20(16)$ & $11(22)$ \\
Extra outpatient care & $12(10)$ & $16(13)$ \\
Other & &
\end{tabular}

In accordance with previous studies, we also found that human error was mainly involved in the causation of the AE and that these are often preventable. ${ }^{15} 26$ Our findings that AEs with organisational causes are mostly preventable are also similar to previous findings. ${ }^{26}$ So even though previous studies used a representative sample of all hospital admissions and we selected a specific patient group, the causes and prevention strategies show similar patterns.

In the present study, the records of all older hip fracture patients admitted in four hospitals in 2007 were reviewed, which resulted in a substantial number of records. Moreover, the four hospitals that participated in the study represent the three hospital types that exist in the Netherlands, namely university, tertiary teaching and general hospitals. Therefore, it seems plausible that the results of this study are of general value to improve the care for older hip fracture patients.

Record review studies have some well-known limitations. First, reviewers have to rely on the information that is available in the record. Only information that is registered by hospital staff during the admission or in the following visits to the outpatient clinic (within 6 months after discharge) can be used for the assessment of the presence of an AE. To illustrate, we found delirium as a complication for $11 \%$ of the patients in our study, which is quite low when compared to some prospective studies which found this complication rate to be $20 \%$ and
Figure 1 Causes of adverse events (AEs, 180 causes in 110 AEs) and preventable AEs (84 causes in 49 preventable).

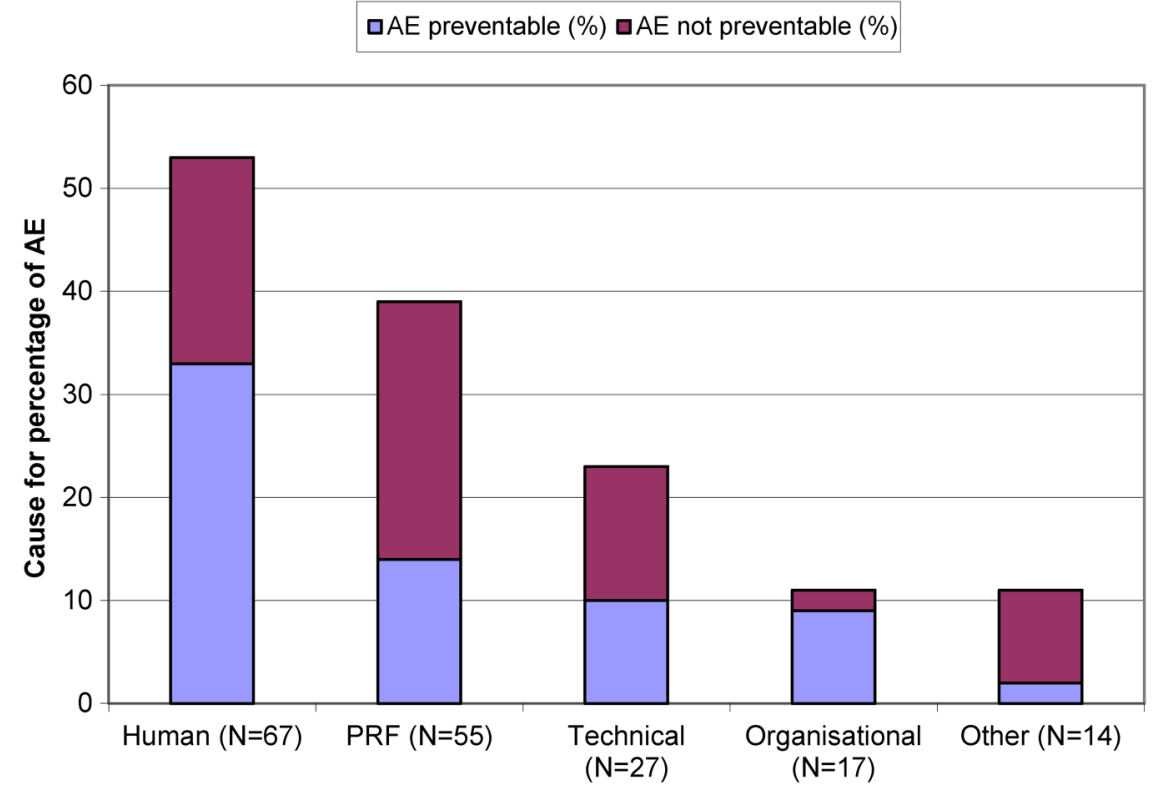


Table 4 Strategies to prevent AEs

\begin{tabular}{|c|c|c|}
\hline Prevention strategy & Description & $\begin{array}{l}\text { Prevention strategy was } \\
\text { selected in following } \\
\text { frequency }(\%) \\
\text { of preventable AEs ( } N=49)\end{array}$ \\
\hline Training & Improving (re)training programmes for skills needed & $25(51)$ \\
\hline $\begin{array}{l}\text { Quality assurance/ } \\
\text { peer review }\end{array}$ & $\begin{array}{l}\text { Continuously monitoring of data on quality based in prespecified } \\
\text { standards and assessment of a health professional's performance by } \\
\text { one or more individuals in the same field }\end{array}$ & $25(51)$ \\
\hline Procedures & Completing or improving formal and informal procedures & $19(39)$ \\
\hline Evaluation & Evaluating the current behaviour regarding safety & $18(37)$ \\
\hline $\begin{array}{l}\text { Information and } \\
\text { communication }\end{array}$ & $\begin{array}{l}\text { Completing or improving available sources of information and } \\
\text { communication structures }\end{array}$ & $11(22)$ \\
\hline Motivation & $\begin{array}{l}\text { Increasing the level of voluntary obedience to generally accepted } \\
\text { rules by applying principles of positive behaviour modification }\end{array}$ & $8(16)$ \\
\hline Technology/equipment & $\begin{array}{l}\text { Redesigning of hardware, software or interface parts of the man- } \\
\text { machine system }\end{array}$ & $4(8)$ \\
\hline Up-scaling & $\begin{array}{l}\text { Handling the problem at a higher organisational level, for example, } \\
\text { hospital department or hospital management level }\end{array}$ & - \\
\hline Financial investment & $\begin{array}{l}\text { Financial investments in required areas, for example, increasing the } \\
\text { availability of facilities and equipment }\end{array}$ & - \\
\hline Personnel & Increasing the number of personnel & - \\
\hline
\end{tabular}

more. $^{27} 28$ Second, the inter-rater agreement between reviewers was moderate in this study and this was also an issue in other retrospective review studies. ${ }^{8}{ }^{9}$ Third, not all relevant information regarding the $\mathrm{AE}$ is registered in the patient record; therefore, gathering information on all contributing factors can become more difficult. Human and patient-related factors that contribute to the causation of an $\mathrm{AE}$ are more regularly reported in the patient record and therefore, these are the most visible factors for reviewers. ${ }^{26}$ Organisational and technical factors are more difficult to find in a patient record as they often indicate more general problems and are, therefore, often reported in other incident-reporting systems within a hospital. ${ }^{26}$ It is recommended for future studies to also include additional sources of information, such as complications discussed during trauma meetings and incident reports, when performing an indepth analysis of (preventable) AEs in older hip fracture patients. This would also provide more insight into more concrete possibilities for prevention of AEs. In the current study, the prevention strategies were the same as in previous retrospective record review studies. ${ }^{9}$ However, it can be argued that these are too generic and it is unknown to what extent they would in fact prevent the AEs. Prospective study designs are more useful for this purpose and are therefore recommended to uncover more detailed information on causes of AEs, and to subsequently select or design prevention strategies tailored to the causes found.

The results of this study show that improvements in patient safety for older hip fracture patients are necessary. We recommend that healthcare professionals should be trained more extensively in how to provide optimal care for this patient group. For example, simulation training could be used to improve skills and for the implementation of new techniques. ${ }^{29}$ Training should not only focus on medical-technical aspects of care but also on identifying patients who may be at risk for complications or AEs. When specific risks are identified and dealt with in individual patients with, for example, a comprehensive geriatric assessment, outcomes may improve. ${ }^{30}$ In addition, peer review of a professional's performance with structured standards can provide useful opportunities to learn from each other. ${ }^{31}$ Regular patient record review, morbidity and mortality meetings, and incident reporting can be usable tools for this goal. $^{32-36}$ More research is needed to investigate the effects of these tools on quality and safety of care, specifically for older hip fracture patients. One important factor to take into account are the specific circumstances and conditions within hospitals. In the current study, all Dutch hospital types were represented to provide a general overview for one patient group. Owing to the limited number of hospitals and preventable AEs in the current study, it was not justified to look at differences between hospital types. This, however, is important when designing interventions for improvement because the setting and context within an university hospital can be very different from those in a general hospital.

To conclude, this study shows that hip fracture patients of 65 years and older suffer from preventable AEs relatively often. More training of healthcare professionals to deal with the specific needs of older hip fracture patients and a focus on quality assurance is needed to reduce the number of preventable AEs in this vulnerable patient group. 
Author affiliations

${ }^{1}$ NIVEL, Netherlands Institute for Health Services Research, Utrecht, the Netherlands

${ }^{2}$ Department of Public and Occupational Health, EMGO Institute for Health and Care Research, VU University Medical Center, Amsterdam, the Netherlands

${ }^{3}$ Department of Trauma Surgery, VU University Medical Center, Amsterdam, the Netherlands

${ }^{4}$ Department of Surgery, Division of Trauma Surgery, University Hospital

Zurich, Zurich, Switzerland

${ }^{5}$ Department of Surgery, Kennemer Gasthuis, Haarlem, the Netherlands

Acknowledgements The authors thank everyone who contributed to the study; the physicians who reviewed the medical records, everyone involved in the data collection, and the four participating hospitals and their staff who facilitated the study.

Contributors CW obtained the funding and supervised all stages of the study. $\mathrm{CW}, \mathrm{HM}$ and $\mathrm{SL}$ designed the study. The acquisition of data was performed by HM, SL and MZ. HM, ML, MZ and CW performed the statistical analysis, the interpretation of the data and drafting of the manuscript. PCJ, GNJ and $\mathrm{MJH}$ were involved in the critical revision of the manuscript for important intellectual content. All authors commented on, revised sequential drafts and approved the final version of the manuscript.

Competing interests None.

Funding This study was funded by ZonMw-the Netherlands Organisation for Health Research and Development, grant number 8140.0004. The funder had no role in the design and conduct of the study, the data collection, analysis or interpretation of the data, preparation, review or approval of the manuscript.

Ethics approval The project and methods have been granted ethical approval by the medical ethical review board of the VU University Medical Center and the scientific committee of the EMGO Institute for Health and Care Research, Amsterdam, the Netherlands.

Provenance and peer review Not commissioned; externally peer reviewed.

Data sharing statement No additional data are available.

Open Access This is an Open Access article distributed in accordance with the Creative Commons Attribution Non Commercial (CC BY-NC 4.0) license, which permits others to distribute, remix, adapt, build upon this work noncommercially, and license their derivative works on different terms, provided the original work is properly cited and the use is non-commercial. See: http:// creativecommons.org/licenses/by-nc/4.0/

\section{REFERENCES}

1. Saltzherr TP, Borghans $\mathrm{HJ}$, Bakker $\mathrm{RH}$, et al. Proximal femur fractures in the elderly in The Netherlands during the period 19912004: incidence, mortality, length of hospital stay and an estimate of the care capacity needed in the future. Ned Tijdschr Geneeskd 2006;150:2599-604.

2. Holt G, Smith R, Duncan $\mathrm{K}$, et al. Changes in population demographics and the future incidence of hip fracture. Injury 2009;40:722-6.

3. Härstedt M, Rogmark C, Sutton R, et al. Impact of comorbidity on 6-month hospital readmissions and mortality after hip fracture surgery. Injury 2015;46:713-18.

4. Orive M, Aguirre U, Garcia-Gutiérrez S, et al. Changes in health-related quality of life and activities of daily living after hip fracture because of a fall in elderly patients: a prospective cohort study. Int J Clin Pract 2015;69:491-500.

5. Castronuovo E, Pezzotti P, Franzo A, et al. Early and late mortality in elderly patients after hip fracture: a cohort study using administrative health databases in the Lazio region, Italy. BMC Geriatr 2011;11:37

6. Dhanwal DK, Dennison EM, Harvey NC, et al. Epidemiology of hip fracture: worldwide geographic variation. Indian J Orthop 2011;45:15-22

7. De Vries EN, Ramrattan MA, Smorenburg SM, et al. The incidence and nature of in-hospital adverse events: a systematic review. Qual Saf Health Care 2008;17:216-23.
8. Brennan TA, Leape LL, Laird NM, et al. Incidence of adverse events and negligence in hospitalized patients. Results of the Harvard Medical Practice Study I. N Engl J Med 1991;324:370-6.

9. Zegers M, de Bruijne MC, Wagner C, et al. Adverse events and potentially preventable deaths in Dutch hospitals. Results of a retrospective patient record review study. Qual Saf Health Care 2009;18:297-302.

10. Baker GR, Norton PG, Flintoft V, et al. The Canadian Adverse Events Study: the incidence of adverse events among hospital patients in Canada. CMAJ 2004;170:1678-86.

11. Davis P, Lay-Yee R, Briant R, et al. Adverse events in New Zealand public hospitals I: occurrence and impact. N Z Med J 2002;115:U271.

12. Michel P, Quenon JL, de Sarasqueta AM, et al. Comparison of three methods for estimating rates of adverse events in acute care hospitals. BMJ 2004;328:199.

13. Thomas EJ, Studdert DM, Burstin HR, et al. Incidence and types of adverse events and negligent care in Utah and Colorado. Med Care 2000;38:261-71.

14. Vincent C, Neale G, Woloshynowych M. Adverse events in British hospitals: preliminary retrospective record review. BMJ 2001;322:517-19.

15. Wilson RM, Runciman WB, Gibberd RW, et al. The quality in Australian health care study. Med J Aust 1995;163:458-71.

16. Wagner $\mathrm{C}$, Van der Wal G. For a good understanding [In Dutch: Voor een goed begrip]. Medisch Contact 2005;60:1888-91.

17. Zegers $\mathrm{M}$, de Bruijne $\mathrm{MC}$, Wagner $\mathrm{C}$, et al. Design of a retrospective patient record study on the occurrence of adverse events among patients in Dutch hospitals. BMC Health Serv Res 2007;7:27.

18. Van Vuuren W, Shea CE, van der Schaaf TW. The development of an incident analysis tool for the medical field. Eindhoven: Eindhoven University of Technology, 1997.

19. Van der Schaaf TW, Habraken MMP. PRISMA-Medical: a brief description. Eindhoven: Eindhoven University of Technology, 2005.

20. Rasmussen J. Skills, rules and knowledge: signals, signs and symbols and other distinctions in human performance models. JEEE Trans Syst Man Cybern 1983;13:257-66.

21. Reason JT. Human error. New York: Cambridge University Press, 1990.

22. MERS TM. Medical Event Reporting System for Transfusion Medicine reference manual version 3.0. New York, 2001. http://www. mers-tm.net

23. Landis JR, Koch GG. The measurement of observer agreement for categorical data. Biometrics 1977;33:159-74.

24. Merten $\mathrm{H}$, Zegers M, De Bruijne MC, et al. Scale, nature, preventability and causes of adverse events in hospitalised older patients. Age Ageing 2013;42:87-93.

25. Sathiyakumar V, Greenberg SE, Molina CS, et al. Hip fractures are risky business: an analysis of the NSQIP data. Injury 2015;46:703-8.

26. Smits M, Zegers M, Groenewegen PP, et al. Exploring the causes of adverse events in hospitals and potential prevention strategies. Qual Saf Health Care 2010;19:1-7.

27. Ringdal GI, Ringdal K, Juliebø V, et al. Using the mini-mental state examination to screen for delirium in elderly patients with hip fracture. Dement Geriatr Cogn Disord 2011;32:394-400.

28. Vochteloo AJ, Moerman S, van der Burg BL, et al. Delirium risk screening and haloperidol prophylaxis program in hip fracture patients is a helpful tool in identifying high-risk patients, but does not reduce the incidence of delirium. BMC Geriatr 2011;11:39.

29. Aggarwal R, Ward J, Balasundaram I, et al. Proving the effectiveness of virtual reality simulation for training in laparoscopic surgery. Ann Surg 2007;246:771-9.

30. Ellis G, Whitehead MA, Robinson D, et al. Comprehensive geriatric assessment for older adults admitted to hospital: meta-analysis of randomised controlled trials. BMJ 2011;27:343.

31. Overeem K, Faber MJ, Arah OA, et al. Doctor performance assessment in daily practise: does it help doctors or not? A systematic review. Med Educ 2007;41:1039-49.

32. Sari AB, Sheldon TA, Cracknell A, et al. Sensitivity of routine system for reporting patient safety incidents in an NHS hospital: retrospective patient case note review. BMJ 2007;334:79.

33. Neale G, Chapman EJ, Hoare J, et al. Recognising adverse events and critical incidents in medical practice in a district general hospital. Clin Med 2006;6:157-62.

34. Institute of Medicine. To err is human: building a safer health system. Washington DC: National Academy Press, 2000

35. Harbison SP, Regehr G. Faculty and resident opinions regarding the role of morbidity and mortality conference. Am J Surg 1999;177:136-9.

36. Benn J, Koutantji M, Wallace L, et al. Feedback from incident reporting: information and action to improve patient safety. Qual Saf Health Care 2009;18:11-21. 